\title{
Compositional Pluralism and Composition as Identity ${ }^{1}$
}

\author{
Kris McDaniel
}

Syracuse University

\section{7-05-12}

(forthcoming in Composition as Identity, eds. Donald Baxter and Aaron Cotnoir, Oxford University Press)

The point of this paper is to assess to what extent compositional pluralism and composition as identity can from a coherent package of views. Since I think there are good arguments for compositional pluralism and I feel the intuition that gives some support to composition as identity, I am motivated to determine this. But regardless of whether you feel attraction to either of these two views, it is worth thinking about how versions of them might interact with each other since doing so is likely to lead to interesting thoughts about parthood and identity.

Let's start with compositional pluralism. Elsewhere I've defended compositional pluralism, which we can provisionally understand as the doctrine that there is more than one basic parthood relation. ${ }^{2}$ (You might wonder what I mean by "basic". We'll discuss this in a bit.) On the metaphysics I currently favor, there are regions of spacetime and material objects, each of which enjoy bear a distinct parthood relation to members of their own kind. Perhaps there are other kinds of objects that enjoy a kind of parthood relation other than the ones enjoyed by material objects and regions of spacetime. Perhaps, for example, there are facts; I've been wavering over whether to embrace these entities for years now. However, I'm reasonably confident that if there are facts than the kind of parthood relation that facts bear to that which composes them is not the kind of parthood relation enjoyed by material objects or regions of spacetime. More on why I am reasonably confident later.

Let's turn to a brief discussion of composition as identity. The primary motivation for the view is an intuition generated by reflection on cases like the following. ${ }^{3} A$ farmer has a farm consisting of six plots, each of which he sells to a different individual. After selling each of the six plots, the farmer sells the farm. The farmer reasons that since none of the plots is identical with the farm, he has (at least) seven items available for purchasing. Something has gone wrong. Intuitively what has gone wrong is that since the farm just is the six plots, by selling the six plots he has sold the farm. (Who then bought the farm? No single individual, but probably the right thing to say is that the six purchasers collectively bought the farm.)

Now, following Theodore Sider (2007), David Lewis (1991) and others, we can distinguish various ways of explicating the slogan that composition is identity, some of them more extreme than others. When explicating the slogan, we should always be guided by the constraint that the explication

\footnotetext{
${ }^{1}$ I thank Aaron Cotnoir and the audience at the Eastern APA's symposium on composition as identity for helpful comments on an earlier version of this paper.

${ }^{2}$ See McDaniel (2004) and (2009).

${ }^{3}$ This sort of example originates from Baxter (1988). See also Lewis (1991) for discussion.
} 
accommodate the intuition just elicited, which in this case is that the farm just is the six plots. If we are not guided by this constraint, we fail to account for this intuition that motivates our search for a theory in which it may find a home. A "moderate" version of composition as identity holds that identity and composition are importantly alike in several ways. What are these ways? Sider lists the following claims as evidence for this important similarity: first, an inheritance of location principle, i.e., that wholes are where their parts are; second, that the intrinsic character of a whole is partially determined by the intrinsic character of its parts); third, that the principles of classical mereology are true, and so composition is unique and unrestricted, and parthood is transitive; third, that the parthood relation is a two-place relation; fourth, that there is exactly one fundamental parthood relation; and finally, that parthood is precise and so is not a source of vagueness.

I won't have much to say about moderate composition as identity for several reasons. First, I'm interested in seeing which versions of compositional pluralism are compatible with what Sider takes to be the strongest forms of compositional identity and which aren't, and why. Second, Sider's formulation of moderate composition as identity has built into it that it is incompatible with compositional pluralism! Or at the very least that it is incompatible with some versions of compositional pluralism; we'll be distinguishing different ways in which a parthood relation might be fundamental or basic, and it is not clear which of these ways Sider has in mind when he says that there is exactly one fundamental parthood relation. Third, Sider's formulation of moderate composition as identity presupposes some views about identity that the friend of composition as identity might not wish to hold. The so-called moderate view might be less moderate in these respects than the officially stronger versions of the view.

For example, the friend of composition as identity might be a friend of ontic vagueness; specifically, she might think that there can be vagueness in identity because the world itself is messed up, rather than blaming some episode of vague identity on a deficiency in our linguistic representations or cognitions. This kind of friend of composition as identity might also think that parthood can be a source of ontic vagueness. Identity and parthood should stand or fall (or sort of stand and kinda fall) together. When I reflect on the intuition that motivates some form of composition as identity, I don't feel pressure (from it) to take a stand on whether parthood is precise; whether ontic vagueness is possible ultimately will be decided by other arguments.

So let's focus instead on what Sider calls strong composition as identity and superstrong composition as identity. Strong composition as identity is the view that, if some xs compose $y$, then those xs are identical with $y$. Superstrong composition as identity is the view that, for any $x$ s and any $y, y$ is composed of the $\mathrm{Xs}$ if and only if $\mathrm{y}=$ the $\mathrm{Xs}$. Note that it is not a trivial consequence of superstrong composition as identity that, whenever there are some xs, there is some y composed of the xs. That is, it is not a trivial consequence of superstrong composition as identity that composition is unrestricted. It is a trivial consequence of moderate composition as identity that composition is unrestricted. So this is a second respect in which the moderate view is more extreme than the superstrong view. The so-called moderate view takes a stand on an interesting mereological question that its supposedly more extreme sibling is silent on. 
Note that there are even stronger views than superstrong composition as identity. As Sider formulates the view, it is merely a claim about mutual entailment. But one might want to go further than that: the slogan that composition is identity suggests some sort of identity between two different relations, composition and identity. We will discuss in more depth later the possibility of even stronger than superstrong versions of composition of identity that follow this train of thought.

For now, let me note that the intuition that motivates some version of composition as identity does not clearly motivate any particular version of the view over the others. Rather, once the initial intuition has motivated one to consider some version of composition as identity, theoretical considerations and perhaps additional intuitions about the specifics of the respective views come into play. So let me pause to be clearer about my goal here. The views just described above either explicitly or implicitly presuppose the falsity of compositional pluralism. So there is no hope of reconciling compositional pluralism with such views. The project will be rather to reconcile compositional pluralism with some view or views that are as supported by the initial intuition that motivates some version of composition as identity. Once that is done, we can let theoretical considerations and higher-order intuitions about theories enter into consideration.

Let's next discuss compositional pluralism, which I informally characterized as the view that there is more than one basic parthood relation. So what do I mean by calling a parthood relation a basic parthood relation? Actually, we should distinguish several different notions of basicality. Some of these notions rely on the contentious and somewhat obscure notion of one property or relation being defined by another. So let's start with that notion. I say that the notion is somewhat obscure because, first, we can form some intuitive judgments about it, such as that being a bachelor is defined by being a male, being unmarried and so forth, that being grue is partially defined by being green, and so forth. But, second, there is no agreed-on account of what it is for one entity in general (rather than one word or expression) to be defined by another entity. ${ }^{4}$ And it's not even clear if the same notion of real definition is in play across our intuitive judgments. Simply consider the difference between the way in which being a bachelor is partially defined by being a male and the way in which being grue is partially defined in terms of being green. Intuitively, being male is among the "conjunctive definition" of being a bachelor while being green is among the "disjunctive definition" of being grue.

I am going to help myself to this notion though, so let me say a few things about what it implies and what I want to remain neutral about. I'm going to focus solely on definitions of properties (or relations) in terms of other properties (or relations). First, definitions are not matters of contingency. If property $F$ is partially defined in terms of property $G$, then, necessarily, property $F$ is partially defined in terms of property $G$. Second, definition implies a modal connection between the items involved in the definition. If property $F$ is defined partially by property $G$, then the satisfaction of one of these properties necessitates some proposition about the satisfaction of the other property. In the case of 'conjunctive definitions', there can be no difference in the pattern of instantiation of $F$ across a given world without there being some difference in the patter of $G$ across a given world. Third, if property $F$ is defined partially by property G, then property G is more "natural" in the sense of David Lewis (1986)

\footnotetext{
${ }^{4}$ For one important and increasingly influential account of real definition, see Fine (1994).
} 
than property $F$ : there is hierarchy of properties in nature with some properties carving at the joints more than others. Fourth, although F's being modally connected with $\mathrm{G}$ in some way and G's being more natural than $F$ or both jointly necessary for $G$ to partially define $F$, they might not be sufficient - I want to leave it open at this juncture whether these conditions can be satisfied without G's being among the definition of F. Finally, I want to remain neutral on questions about parthood and identity among properties, which is somewhat ironic given the subject matter of this paper. I want to remain neutral on whether we should think of $G$ as literally being a part of $F$ when $G$ is among the definition of $F$. And I want to remain neutral on whether we should think of $G$ as being numerically identical with some complex property consisting of the properties that are collectively G's definition.

That said, affirming what I want to (for now) remain neutral on might well be theoretically useful - perhaps what distinguishes pairs of properties that are merely modally connected and asymmetrically ranked on the naturalness from properties from pairs of properties such that one is among the definition of the other just is the fact that there is a further relation, a parthood relation, in play in the second case: that which is among the definition of a property is that which is among its parts. I think this actually a pretty attractive view, especially if you are taking seriously the idea that definitions of a property are constitutive analyses of a property, where the latter reveals the mereological structure of the property in question. Moreover, if you are a compositional pluralist, as I am, you might also think that the different kinds of real definition, such as conjunctive or disjunctive definitions, might correspond to distinct kind of parthood relations. So although I am officially neutral on whether mereological relations are part of(!) what it is to be a real definition, I recommend this question for further thought.

With these provisional remarks in mind, let's turn to characterizing different notions of basicality. We need some sort of notion of basicality to distinguish compositional pluralism from compositional monism. You aren't a compositional pluralist simply by believing in different parthood relations: everyone should believe that there are different parthood relations! But some of these parthood relations are defined in terms of other parthood relations. For a trivial example, consider the notion of immediate parthood: $\mathrm{x}$ is an immediate part of $\mathrm{y}$ just in case $\mathrm{x}$ is a proper part of $\mathrm{y}$ and there is no other proper part of $y, z$, such that $x$ is a part of $z$. Immediate parthood is partially defined by an antecedent parthood relation, and so in no sense is it a basic parthood relation. Let us say that a parthood relation $\mathrm{R}$ is $d$ p-basic just in case there is no other parthood relation $\mathrm{R}^{*}$ such that $\mathrm{R}^{*}$ is among the definition of $\mathrm{R}$. (The ' $\mathrm{dp}$ ' is to help the reader remember we are considering relations that are not defined in terms of other parthood relations.)

A dp-basic parthood relation might fail to be basic in other senses though. Say that a parthood relation is $n$-basic just in case there is no other parthood relation that is more natural than it. A dp-basic parthood relation might fail to be $n$-basic, but given what I have said earlier about definition, any $n$-basic parthood relation must be a d-basic parthood relation. Finally, let us say that a parthood relation is fundamental just in case no property or relation is more natural than it. Any fundamental parthood relation must be an $\mathrm{n}$-basic parthood relation, but the converse is not true as a matter of definition. 
We have three notions of increasing strength, each of which corresponds to an interesting kind of compositional pluralism. Let's say that dp-compositional pluralism is the view that there is more than one dp-basic parthood relation; let's say that $n$-compositional pluralism is the view that there is more than one b-basic parthood relation; let's say that $\mathrm{f}$-compositional pluralism is the view that there is more than one fundamental parthood relation. In my earlier work on compositional pluralism, I was not always careful to distinguish these notions of basicality.

We now have on the table various forms of composition as identity and compositional pluralism. Let's turn now to the question of compatibility. There is no easy or simple answer to the question, and in fact it will be helpful to have some further distinctions on the table, which we will elicit by characterizing some specific instances of specific forms of compositional pluralism.

In what follows, whenever I introduce into discussion parthood relations P1, P2, and so forth, I will also help myself to the correlative relations of P1-composition, P2-composition, and so forth. I am effect assuming that, whenever there is a basic form of parthood, there is also a corresponding form of composition. It is this assumption that leads me to call my view "compositional pluralism" rather than simply "parthood pluralism". But the assumption is not trivial. An alternative view worth considering but won't be considered here - is the view that, although there are many different basic parthood relations, there is only one important composition relation, and this composition relation is defined in terms of all of the basic parthood relations. Perhaps this sort of view would have many of the positive features of compositional pluralism while, in some sense, still being a version of compositional monism. And it might be that this kind of view would be easier to reconcile with composition as identity than the versions of compositional pluralism I consider below.

Lets' start by considering a version of compositional pluralism according to which there are two dp-basic parthood relations, P1 and P2, that have the following features. First, the fields of their application are totally distinct: that is, all the things that stand in the P1 relation to something form a set; all the things that stand in the P2 relation to something form a set; and these sets are completely disjoint. Second, the logical form of P1 and P2 is the same, and moreover, both are two-place relations. Let's even assume that the two relations play by the same rules, and that the rules are something like a restriction of classical mereology to within the items in either set. That is, both relations are transitive, have a corresponding composition relation that is unique, and obey a restricted version of universal summation: any xs within the set of things corresponding to P1 have a P1-sum, and any ys within the set of things corresponding to P2 have a P2-sum.

This sort of compositional pluralism can fairly easily accommodate various forms of composition as identity. Let strong compositions as identity be the conjunctive claim that, if xs P1-compose $y$, then xs are identical with $\mathrm{y}$, and if $\mathrm{xs} \mathrm{P} 2$-compose $\mathrm{y}$ then $\mathrm{xs}$ are identical with $\mathrm{y}$. Compositional pluralism is obviously compatible with a view. Moreover, as far as I can tell, this kind of view can receive as much evidential support from the intuition that motivates strong composition as identity but without presupposing that there is exactly one dp-basic parthood relation. Suppose that the two composition relations are such that one is defined on the field of material objects while the other is defined on the field of classes or sets. Given strong compositions as identity, the farmer's field just is the six plots that 
compose it (in the way that material objects are composed). And a set just is the singletons that compose it (in the way that sets are composed). These intuitions about farmers' fields or sets and their subsets do not favor a version of composition as identity according to which there is exactly one dpparthood relation over a view in which there is more than one.

Something similar is true of superstrong compositions as identity, which is the view that, $x$ are identical with some y just in case, either, the xs P1-compose y or the xs P2-compose y. In no way do the intuitions that 'composition is identity' immediately favor superstrong composition as identity over superstrong compositions as identity.

What about views even stronger than superstrong versions of composition as identity? Friends of composition as identity probably find attractive the idea that composition and identity are both special cases of a more general relation, which we can call many to many identity. Here's the most obvious way to flesh out this thought. There is a relation, call it plural identity, which can relate many things to many things, one thing to one thing, and many things to one thing. The relation is represented by the open sentence ' $x$ s \# ys'. Ordinary numerical identity is defined in terms of plural identity in the following way: $x=y=d f$. $x \# y$; the use of singular variables presupposes that there is not more than one of $x$ or $y$, and hence such a clause is not explicitly required. Composition is defined in terms of plural identity: $x$ s compose $y=d f$. $x$ \# $y$. And to be a part of $y$ is simply to be among the things that are $y$. Let's call this view reductive composition as identity.

On reductive composition as identity, there is exactly one $\mathrm{dp}$-basic parthood relation. Since there is exactly one dp-parthood relation, we can conclude that it is n-basic as well. But there are no fundamental parthood relations, since the sole $n$-basic parthood relation is partially defined by manymany identity, and so is less natural than many-many identity, and so is not a perfectly natural relation.

The friend of compositional pluralism can mimic reductive composition as identity in the following way. Let's continue to assume that we are dealing with P1-composition and P2-composition, and let's further stipulate that P1-composition is the kind enjoyed by material objects and P2composition is the kind enjoyed by sets. Let reductive compositions as identity be the conjunction of the following views: the xs P1-compose $y=d f$. xs \# $y$ and the $x s$ are material objects; the xs P2-compose $y$ =df. xs \# $y$ and the xs are sets. On this view, there are two dp-basic parthood relations, although neither is a fundamental parthood relation. Because there are two of these relations, we aren't in a position given the information provided to discern which of them is an n-basic parthood relation, although at least one of them must be. (They are both n-basic, if they are equally natural.) And as before, the intuition favoring some form of composition as identity does not by itself favor reductive composition as identity over reductive compositions as identity.

The intuition favoring some form of composition as identity does not tell against this form of compositional pluralism. Rather, the problem for this kind of compositional pluralism is that it is hard to see what could motivate believing it. Suppose that one wants to rule out certain putative composite objects which would be very strange were they to exist, for example, wholes made out of sets and material objects. Compositional pluralism of any sort is not needed to do this; a simple restriction on a 
single parthood relation that rules out wholes composed of things from different categories suffices. Compare: one would never endorse pluralism about identity simply in order to rule out the possibility that a present material object, say your desk, will be identical with a future set, say the set consisting of the first human beings on the planet Mars. (Maybe desks can become other kinds of furniture, or even mere heaps of wood and metal, but they can't become sets!) Distinct criteria of identity for different kinds suffice here, and so positing distinct identity relations solely for this reason is unmotivated. ${ }^{5}$

So before we move on, it would be good to see briefly how such a view could be independently motivated. So I will sketch one possible motivation; I am not going to offer an argument here, but rather I will try to get a view on the table in which this kind of compositional pluralism has a natural home. I like a metaphysics on which some things are more fundamental than others and on which only fundamental substances can enjoy fundamental properties and relations. There are many ways to understand fundamentality, and I needn't take a stand here on which way is best, but on the way of understanding I prefer, less fundamental things are less real than more fundamental things. ${ }^{6}$ I think that some material objects, such as persons and living organism, are fully real and have parts, and I am also inclined to think that the parthood relation enjoyed by material objects is a fundamental relation. But entities like shadows or holes are less fundamental than the objects that produce them or host them. (In McDaniel (2010a) I called shadows and holes, as well as cracks, fissures, and other "negative" entities "almost nothings", a term which aptly describes their ontological status.) Shadows also have parts, although the fail to be fully real - the shadow cast by my arm is a part of the shadow cast by my body. Similarly, holes are less real than their hosts, but holes can have parts as well, since a part of a hole can be filled. I do not think there is much hope in being able to define the parthood relation that negative entities bear to each in terms of the parthood relation enjoyed by material objects. But given that nonfundamental entities cannot bear fundamental properties in general, it follows that the parthood relation enjoyed by material objects cannot be the parthood relation enjoyed by almost nothings. Since neither parthood relation is definable in terms of each other, a form of compositional pluralism is true: there are two dp-basic parthood relations. However, it might still be the case that these two parthood relations have the same logical form and obey similar axioms. So there is a way that this kind of compositional pluralism, which I have argued is compatible with composition as identity, could be motivated.

Of course, a kind of compositional monism might also be true: if our ontology consists solely in substances and negative entities, then there definitely is exactly one n-basic parthood relation, which might also be the sole fundamental parthood relation, namely the parthood relation defined on material objects. So this particular ontology motivates only one of the weaker versions of compositional pluralism. But it is still a form of compositional pluralism that can be independently motivated, and since it is compatible with most interesting versions of composition as identity, our time has not been wasted by discussing it in depth.

\footnotetext{
${ }^{5}$ See Hawley (2006) who raises similar worries about certain motivations for believing in compositional pluralism.

${ }^{6}$ See McDaniel (2010a) for a contemporary take on degrees of reality, and my unpublished manuscript for further defense.
} 
Let's turn now to a stronger form of compositional pluralism according to which there are at least two fundamental parthood relations and hence two $n$-basic parthood relations. Since an ontology containing almost nothings cannot motivate such a view, we might wonder what could. My view is that this kind of compositional pluralism is motivated when the parthood relations either play by different rules or have different logical forms. ${ }^{7}$ Let's say that a rule governs a certain feature if that rule is a necessary truth that can be stated using only logical vocabulary, including variables which are restricted to the field of application of the feature, and some expression that represents the feature. Two features play be the same rules just in case the statements of these rules differ only with respect to the presence of the respective expression that represents the respective feature or with respect to range of the variables. I don't want to say much about the logical form of features here, but the possession of different adicities, that is, number of objects needed to instantiate the feature, is a sufficient condition for two features to differ with respect to logical form. The guiding intuition here is that fundamental features enjoy a kind of uniformity across their instances. If some feature could obey different rules in different contexts, it would lack this kind of uniformity: the principles partially constitutive of what it is to be that features shouldn't change in this way (at least not if the feature is fundamental). I think the intuition with respect to logical form is even more robust: what could be a more radical way of differing across instances than always being satisfied by exactly two things among some field of application and always being satisfied by exactly three things among some other field of application?

Let me briefly clarify one thing about the criterion that appeals to difference in logical form. The criterion does not tell us that there cannot be fundamental properties that are irreducibly plural. Consider the property of being co-linear. $X$ and $y$ can be co-linear, as can $x, y$ and $z$, and so can $w, x, y$, and $z$, and so-forth. We shouldn't conclude however that co-linearity is a variably polyadic relation and so can't be a fundamental relation. Rather, we should hold that co-linearity is a one-place monadic plural property. Being co-linear does not in any way seem like a mere disjunction of relations of different adicities. On the other hand, the disjunction of the 3-place parthood relation enjoyed by material objects and the 2-place parthood relation enjoyed by regions of spacetime does seem more akin to a mere disjunction. ${ }^{8}$

Consider material objects and the regions of spacetime they occupy, and their corresponding parthood relations, m-parthood and $r$-parthood. I do not believe that $m$-parthood and r-parthood play by the same rules. For example, although any regions uniquely $r$-compose something, it's not the case that whenever you have some material objects, you have something that they $\mathrm{m}$-compose. There might be a 'generic' parthood relation enjoyed by both material objects and regions of spacetime, but in my view, this relation is a mere disjunction of the two more natural parthood relation, and hence isn't even a dp-basic parthood relation.

Let us suppose that both composition relations are extensional. If this is the case, then I see no reason to think that this form of compositional pluralism, according to which there is more than one

\footnotetext{
${ }^{7}$ See McDaniel (2009) and McDaniel (2010b) for further discussion of these two ways in which pluralism can be motivated.

${ }^{8} \mathrm{My}$ preferred view is that this relation is "unified by analogy" and hence is more natural than a mere disjunction of two relations, but less natural than either of its "disjuncts". For more on this idea, see McDaniel (2010b).
} 
fundamental parthood relation, is at all incompatible with the intuitions that motivate some form of composition as identity. As noted earlier, superstrong composition as identity does not imply that composition is unrestricted, and it should be noted now that reductive composition as identity also lacks this implication. The belief that there is nothing composed of the farmer's field and the noses of everyone in this room in no way undercuts the intuition that the farmer's field just is the six plots of land. So the fact that only one relation obeys universal composition across its field of application provides no reason by itself to deny some form of composition as identity. And given just what has been said so far, there is nothing to stop this kind of compositional pluralist from endorsing variants of strong compositions as identity, superstrong compositions as identity, or even reductive compositions as identity.

Of course, if one of the fundamental composition relations is not extensional, problems for reconciling this form of compositional pluralism with composition as identity do arise. Suppose the xs $\mathrm{m}$ compose $y$, and the xs m-compose $z$, and yet $y$ is not identical with $z$. But, if $y$ is identical the $x s$ and $z$ is identical with xs, it is very hard to see how y could fail to be identical with $z$. (Shouldn't identity still, in some sense, be transitive even in a context in which we are considering identity as possibly relating many things to one thing?)

But note that the difficulty here is the failure of extensionality per se rather than compositional pluralism per se. We can see this simply by considering versions of compositional monism according to which extensionality fails, perhaps because the statue is not identical with the lump that constitutes it, although both the lump and the statue are composed by the same atomic parts. There might be exactly one fundamental parthood relation, but if that parthood relation fails to be extensional, the odds for any kind of composition as identity being true look pretty dim.

What about versions of compositional pluralism in which the various relations differ with respect to their logical form?

I'm inclined to think that the parthood relation enjoyed by material objects is a three-place relation with a slot reserved for either times or regions of spacetime. (I like endurantism and think objects can change parts while still persisting.) But the parthood relation enjoyed by regions of spacetime is a two-place relation. Can this kind of compositional pluralism be reconciled with composition as identity?

I think the answer is yes, but I suspect only by accepting a corresponding pluralism about identity as well according to which there are two fundamental identity relations, one of which is threeplace and has a slot reserved for either times or regions of spacetimes, while the other is a two-place relation. Material objects, on this view, enjoy temporally-relative or spatiotemporally-relative identity. ${ }^{9}$

\footnotetext{
${ }^{9}$ For defenses of temporally relative identity, see Myro (1985) and Gallois (1998). For a different way of approaching the question of composition as identity via temporary identity, see McDaniel (forthcoming).
} 
If you are an endurantist and you are attracted to composition as identity, but you think things can change parts over time, you probably should be looking pretty seriously at a view like this. ${ }^{10}$ And it's not clear to me that such a view isn't motivated by the intuitions for composition as identity. When the farmer sells the six plots, the farmer sells the farm. But if the farmer had refrained from selling the six plots, and then expanded the farm by adding another plot, and then sold the six plots, the farmer would not then have sold the farm. Although previously the six plots were the farm, later the farm became more than just the six plots. The kind of many to one identity enjoyed by material objects is relative to a time.

Identity pluralism is of course incredibly contentious, and so is relativizing identity to times. But let me focus on the latter: note that once again, one could be a compositional monist and think that the fundamental parthood relation is relative to a time, but if one also wants to endorse some form of composition as identity, relativizing identity to a time is going to be hard to avoid. It is not compositional pluralism per se that is incompatible with composition as identity, but rather specific versions of compositional pluralism that take on commitments that a compositional monist might also take on.

There are of course many more forms of compositional pluralism than the ones discussed here, but obviously it is not possible to describe them all. Still some general lessons may be drawn. Many interesting versions of compositional pluralism are compatible with many interesting versions of composition as identity. Some versions of compositional pluralism aren't compatible with any interesting version of composition as identity, but that is also true of some versions of compositional monism. That this is the case should now be obvious, but l'll admit to originally being skeptical of the possibility of reconciliation. I'm now a bit in the dark about why I was previously doubtful. Recall the case of the farmer's field and the six plots that compose it. The original intuition was an intuition about the whole and its parts, to the effect that the whole really is nothing other than its parts. The intuition wasn't really about parthood per se, and it didn't contain the thought that parthood itself had any sort of unitary or non-disjunctive nature.

Bibliography

Baxter, Donald. 1988. "Identity in the Loose and Popular Sense", Mind 97: 775-582.

Fine, Kit. 1994. "Essence and Modality", Philosophical Perspectives 8: 1-16.

Gallois, Andre. 1998. Occasions of Identity: A Study in the Metaphysics of Persistence, Change and Sameness. Oxford University Press.

Hawley, Katherine. 2006. "Principles of composition and criteria of identity", Australasian Journal of Philosophy 84: 481-493.

Lewis, David. 1986. On the Plurality of Worlds, Blackwell publishing.

Lewis, David. 1991. Parts of Classes, Blackwell Publishing.

\footnotetext{
${ }^{10}$ See Merricks (1999) for discussion of a related point.
} 
McDaniel, Kris. 2004. "Modal Realism with Overlap", Australasian Journal of Philosophy 82.1, pp. 137152. (This is reprinted in Lewisian Themes, edited by Frank Jackson and Graham Priest, Oxford University Press, September 2004.)

McDaniel, Kris. 2009. "Structure-Making", Australasian Journal of Philosophy 87.2: 251-274.

McDaniel, Kris. 2010a. "Being and Almost Nothingness", Nous 44.4: 628-649.

McDaniel, Kris. 2010b. "A Return to the Analogy of Being", Philosophy and Phenomenological Research 81.3: 688-717.

McDaniel, Kris. forthcoming. "Parthood is Identity?", in Mereology, Topology, and Location, edited by Shieva Kleinshmidt, Oxford University Press.

McDaniel, Kris. unpublished. "Degrees of Being".

Merricks, Trenton. 1999. "Composition as Identity, Mereological Essentialism, and Counterpart Theory," Australasian Journal of Philosophy 77: 192-195.

Myro, George. 1985. "Identity and Time", in Philosophical Grounds of Rationality: Intentions, Categories, Ends, edited by R. Grandy and R. Warner, Oxford University Press.

Sider, Theodore. 2007. "Parthood", Philosophical Review 116: 51-91. 